equal volume of water and again apply the Kelling test, which, if positive, represents .14 per cent. or fourteen points.

Dilutions can also be made by making the second dilution one-half the volume of water in which a positive reaction represents at least ten and one-half points or one-fourth the volume of water, in which a positive reaction represents at least eight and three-fourths points, and so on. The amount of lactic acid thus obtained is subtracted from the free hydrochloric acid obtained and the result is approximately correct for free hydrochloric acid.

The question now presents itself, Will a quantity of lactic acid not sufficient to give the test with di-methylamido-azo-benzol unite with the hydrochloric acid in producing a vitiated result? To determine this point I added .05 per cent. of lactic acid to a solution of hydrochloric acid of known strength, titrated, using dimethyl-amido-azo-benzol as an indicator and obtained practically the same readings as before adding the lactic acid.

By this method of procedure the ordinary di-methylamido-azo-benzol indicator can be used at all times, and when lactic acid is present the results can be sufficiently rectified for clinical purposes.

612 North Taylor Avenue.

\section{THE BLOOD PLATES.}

THEIR FNUMERATION IN PIIYSIOLOGY AND PATHOLOGY. GEORGE T. KEMP, M.D., PH.D.

Professor of Physiology, University of Illinois.

WITH TIE COLLABORATION OF HENRIETTA CALHOUN, A.M., AND CHESTER E. HARRIS, A.M.

CIIAMPAIGN, ILL.

(Concluded from page 1027.)

Bizzozero.- The reagent which commonly goes by the name of Bizzozero's fluid consists of a 0.75 per cent. aqueous solution of sodium chlorid, to which is added a small amount of methyl violet (about 1 part to $5,000) .{ }^{12}$ This was not recommended by him for numeration work. Bizzozero preferred the Laker method, and the fluids he used for determining the ratio of the plates to the red corpuscles are described differently in different publications we have consulted. In referring to some of his old experiments made by himself in 1884, and in collaboration with Sanquirico in 1886 , Bizzozero ${ }^{14}$ states that the fluid used was made in accordance with the following formula:

1.0 per cent. osmic acid, aqueous solution...... 1 part.

0.7 per cent. sodium chlorid, aqueous solution...... 3 parts.

In referring to the same experiments in another article he ${ }^{28}$ gives the percentage of the sodium chlorid solution as 0.1 per cent. This we take to be a misprint and regard the 0.7 per cent. as more probably correct. Pizzini $^{20}$ quotes from Bizzozero's text-book ${ }^{30}$ that the fluid recommended is 1 per cent. osmic acid colored with methyl violet. For criticisms on these fluids see acid, osmic, above.

In addition to these osmic-acid fluids, Bizzozero also recommends a 14 per cent. solution of magnesium sulphate in water. We have tried this and find that, while it preserves the plates, the red corpuscles are distorted and sometimes buds are shed from them.

28. Bizzozero: Virchow's "Festschrift," 1891, p. 472.

29. Pizzini : Riforma medica, 1894, vol, 11, p. 376.

30. Bizzozero: Microscopic Clin., Third Edition. Year, page and full title not given.
Brodie and Russell.-Brodie and Russell ${ }^{20}$ have usually employed a mixture of equal parts of glycerin saturated with dahlia and a 2 per cent. aqueous solution of sodium chlorid. This gradually decolorizes the red corpuscles, but the ratio can be determined before this occurs. This liquid is used without a counting chamber. We have tried this method and found that it gave good results.

Cadet.-Cadet ${ }^{31}$ used iodized serum and also a fluid which he calls "liquid B," for which we quote his formula:

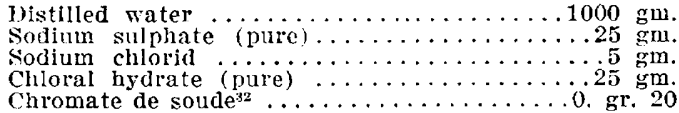

All the ingredients must be pure. The chromate de soude must be weighed exactly. Filter each time before using. We have not tried this fluid. It was tried by van Emden, who says he prefers the Prus fluid without stating any definite objection to the fluid of Cadet.

Chromates.-With Müller's fluid and potassium bichromate solutions ( 6 per cent., 4 per cent. and 1 per cent.), we found that granules are formed after a time, and these, under a low power, may cause confusion in counting the blood plates.

Determann.-In most of his experiments, Determann used a 0.9 per cent. aqueous solution of sodium chlorid, colored with methyl violet. This is practically the same as Bizzozero's old fluid. It is not a fixative, and our experience with it leads us to condemn it for numeration purposes, though we can recommend it as a convenient fluid for examining the plates. It retards their breaking down, but does not prevent it. Determann's method has been fully discussed in this paper. ${ }^{33}$ Determann also used a solution containing 1 per cent. sodium chlorid and 5 per cent. potassium bichromate. We have not tried this particular combination. Our experience with chrome-salts is given above under Chromates.

Fusari.-Fusari ${ }^{23}$ used the following fluid: Equal parts of 1 per cent. osmic acid and 0.75 per cent. $\mathrm{NaCl}$ solution, colored with enough methyl violet to give the mixture a slight violet tint (leggera tinta violetta). Later he substituted an aqueous solution of $\mathrm{Na}_{2} \mathrm{SO}_{4}$ (specific gravity 1025) for the 0.75 per cent. $\mathrm{NaCl}$ solution in the above, and says that this makes a firstclass preservative fluid (un ottimo liquido conservatore). Even with this he records cases where the plates were clumped in groups and a fresh preparation had to be taken. He counted 400 small squares of the ThomaZeiss instrument.

Mayem.-Hayem's ${ }^{34}$ fluid A, which he recommends for counting the red corpuscles, and which is generally known as Hayem's fluid, is made in accordance with the following formula:

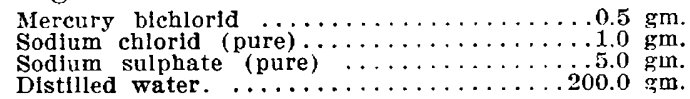

It is not a good fluid for counting the blood plates, as it often produces a precipitate which is confusing. The fluid used by Hayem in most of his blood-plate numerations was the iodized serum of Max Schultze. But this is difficult to prepare and when not properly made it is unfit for use.

For Schultze's iodized serum Hayem substituted the

31. Thise de Paris, 1880 , pp. $36-38$

32. 'This line is copied literally from Cadet's recipe. We are in doubt as to whether he means chromate or bichromate. The "0. gr. $20^{\prime \prime}$ is also exactly quoted.

33. See H, under Methods.

34. Hayem: Arch de Physiol. 1878, vol. $\mathbf{7}$, p. 700 ; also Hayem, Du Sang, Paris, 1889 , pp. 16, 28, 31 and 38 . 
amniotic liquid of cows and of sheep. This is carefully prepared in the winter and kept in Pasteur flasks until needed. He uses "eau oxygenée" (peroxid of hydrogen) as a preservative, and when blood plates or leucocytes are to be counted he adds a small amount of methyl violet $5 \mathrm{~B}$. Hayem also used diabetic urine of specific gravity at least 1039 . To this was added 6 per cent. of "eau oxygenée à 12 degrés."

The latest fluid which we have found Hayem ${ }^{35}$ to recommend is one which, he says, is particularly adapted to human blood. It is made by preparing an iodin solution according to the following formula:

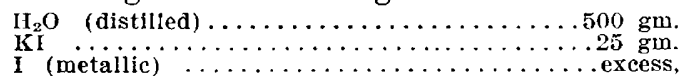

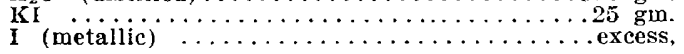

and replacing the mercury bichlorid in fluid $\mathrm{A}$ by 3.5 c.c. of this iodin solution.

Of the several fluids which Hayem has used we have tried only one, viz., his fluid A. We agree with him that it is not to be recommended for blood-plate numerations on account of the precipitates which it produces.

'Those fluids which require elaborate methods for preparation and for preservation are obviously objectionable from a standpoint of convenience.

Helber.-Helber, ${ }^{10}$ continuing some older work of Pratt, each in Professor Krehl's laboratory at Tübingen, used a 10 per cent. solution of sodium metaphosphate. Each of these observers found that the blood plates floated in this liquid, and so it can not be used with the Thoma-Zeiss counting chamber, as the plates and the lines are not in focus at the same time. This led to the construction of a special counting chamber by Helber. ${ }^{36}$ Even with this special instrument, Helber does not say that the objection is entirely removed. ${ }^{37}$ In using as high an objective as a twelfth, we feel that any fluid of such high specific gravity as to allow the blood plates to float would be extremely inconvenient and would probably introduce an error even when the counting chamber was dispensed with, ${ }^{38}$ for the thickness of the layer of blood would be sufficient to keep the plates and the red corpuscles out of distinct focus at the same time. The solution does not keep well, it "must be made fresh every three days, and filtered each time before using."

Kemp and Calhoun.-See under "Aldehyd, formic." Laker.-Laker ${ }^{39}$ used Hayem's fluid A. See under Hayem.

Metaphosphates.-See Helber, Pratt, and Richardson.

Muir.-Muir ${ }^{40}$ tried a number of different fluids and prefers an aqueous solution of sodium sulphate (specific gravity 1022), colored with methyl violet. We have tried this fluid, combined with formaldehyd, as recommended by Marcano for red corpuscle numerations, and find it effective in that form. We have not tried it in the form used by Muir.

Petrone.-Petrone ${ }^{41}$ uses an osmic acid fluid containing salt. We do not find a definite formula, but in one place he gives the strength of the osmic acid as $1: 300$.

Pizzini.-Pizzini ${ }^{20}$ used 1 per cent. osmic acid colored with methyl violet. He says that antipyretics, especially phenacetin or antipyrin, 25 centigrams to 100 c.c. of water, using heat to effect the solution, have the power

35. Hayem: "Leçons sur les maladies du sang," Paris, 1900 , p. 103.

36. See J. under Methods.

37. Bel dieser Kammer fillt die lästige Durchmusterung der verschiedenen Höhenlagen fast weg. (The Italics are ours.)

38. See $K$. under Methods.

39. Laker: Sitzungsberichte der Kalserl. Akad, Vienna, Part lit,

1886 , vol. xelil, p. 22 , footnote 3 .

40. Muir : Jour. of Anat. and Physiol., 1891, vol. xxv, p. 259.

41. Petrone: Il Morgagni, 1897, vol. lif, pp. 308, 399 and 409. to preserve blood plates almost like a solution of osmic acid.

Pratt.-Pratt ${ }^{9}$ first used a 10 per cent. solution of sodium metaphosphate. $\mathrm{He}^{9}$ later used a 5 per cent. solution of the same salt, and in his last communication, ${ }^{42}$ presented at the same meeting with this work, he recommends a fluid made in accordance with a formula which we quote as follows:

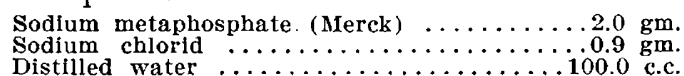

We have never used sodium metaphosphate solutions for numeration experiments, but we have had considerable experience with them in repeating the work of Deetjen on the alleged ameboid movements of the blood plates. ${ }^{43}$ We have found that all these solutions are very prone to ferment and to become mouldy. Helber states that they should be made fresh at least every three days, while Richardson says a week. Pratt's work has been painstaking and valuable, and his partiality for sodium metaphosphate leads us to believe it may have some special merit. We, therefore, propose to try this salt in combination with sodium chlorid and formaldehyd. This would have the double advantage of placing such a fluid in the more certain class of fixatives and of preventing fermentation and molding altogether.

Prus.-The original paper of Prus is in Polish, so we were not able to consult it. The only German abstract ${ }^{44}$ which we have seen does not give the method in detail, but van Emden 4 recommends the use of Prus' fluid, so we take it for granted that he used the Prus method. This is really the pipette method, but using a fluid which preserves the plates and decolorizes the red corpuscles. With the red corpuscles thus eliminated from obstructing the view, one can use a dilution as low as $1: 20$ or even $1: 10$. According to van Emden, this brings an enormous number of plates into the field and reduces the error so greatly that the plates which are lost by sticking to the sides of the pipette may be ignored. By using a refrigerated pipette, van Emden can bring this error practically to nil; for at zero centigrade the plates will not adhere.

The recipe for Prus' fluid, as quoted from van Emden, is as follows:

Sol. acidi osmicl ( 1 per cent.) .......... 10 c.c Sol. acidi chromicl $(0.1$ per cent. $) \ldots \ldots \ldots \ldots 10$ c.c. Acidi aceticl glacial .............. 1 c.c.

We have not used this method, but we are impressed with the advantage of counting a large number of plates and thus reducing the error. The inconvenience of refrigerating the pipette will always be a drawback in clinical work, and without this we should always distrust the method, for the error varies with the temperature and the time it takes to measure the blood. Moreover, the pipette method not only holds back plates by adhesion, but tends to clump those which go free. In using Prus' fluid, van Emden mentions a precaution which is significant, and which tends to shake one's confidence in the method. He says that vigorous shaking in the melangeur produces a large number of small highly refracting bodies which might be mistaken for blood plates. He attributes what he calls a high count by Prus (500,000 per cu. mm.) to this cause

Reyne--Reyne ${ }^{\mathbf{4 5}}$ criticises the iodized serum of Max Schultze (used by Hayem) as a fluid for examining or

42. Pratt: The Jodrnal A. M. A., 1905, vol. xl, p. 2002.

43. Kemp and Stanley : Amer. Jour. of Physiol., 1901, vol, v, p. iv.

44. Centralbl. $f$. $k$. Med., 1887, vol, vili, p. 469. The original

paper appeared in Medycyna (Polish), 1886, Nos. 39 and 40.

45. Reyne: Thèse de Paris, 1881, pp. 18-19. 
counting the plates. He says it is unreliable. "Some specimens are good and others are absolutely bad without one's knowing why or how to remedy it." Reyne uses diabetic urine containing from 6 to 7.5 per cent. glucose. This is boiled and filtered through animal charcoal. To this liquid thus decolorized is added 5 to 6 per cent. of its weight of "eau oxygenée à $12^{\circ}$ " (peroxid of hydrogen?). This preserves the corpuscles and does not deform the plates. The only objection that he urges to it is that it forms small bubbles of gas on standing. See, also, Hayem above.

Richardson.-Richardson ${ }^{46}$ used Laker's method with the following solution:

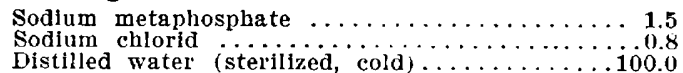

Filter and add, if desired, a small amount of gentian violet or brilliant cresyl blue. The solution will not keep well for over a week and should not be used if mold develops in it.

Salvioli.-Salvioli ${ }^{16}$ nsed a fluit made according to the following formula :

Osmle acid (1 per cent.) $\ldots \ldots \ldots \ldots \ldots \ldots \ldots 1$ part.
Sodium cblorid (0.7 per cent.)

Sodium chlorid ( 0.7 per cent.) $\ldots \ldots$
Aqueous solution of methyl violet, $q$. s.

'This is practically the same as Bizzozero's counting fluid. See Bizzozero and Acid, osmic, above.

Van Emden.-See Prus, above.

\section{AUTHORS' METHOD IN DETAIL.}

The fluid used in this method has been described under Aldehyd. The following apparatus and accessories should be ready for use before making the puncture to draw the blood:

Miscroscope with nose-piece, and at least one objective of low power, not lower than two-thirds; and one of high power, not lower.than a one-sixth. A Thoma-Zeiss outfit for counting red corpuscles (two counting chambers would be preferable). Several thoroughly cleaned watch glasses (deep facet-form, about $25 \mathrm{~mm}$. diameter, most convenient). One such watch glass full of the aldehyd fluid. One such watch glass containing three or four drops of this fluid. A glass rod about $5 \mathrm{~mm}$. in diameter, about $15 \mathrm{~cm}$. in length, and rounded at the ends. A clean soft towel. A clean handkerchief or rag, soft and unstarched.

In collecting blood for counting the blood plates, the great desideratum is that all parts of the blood drop shall come in contact with the aldehyd before touching any foreign object (surface of skin, glass, etc.). This is really a sine qua non, for otherwise some of the blood plates will adhere to the foreign body, and of those which go free some are sure to be found clumped.

If the finger is to be used for the puncture, the hands are washed with soap and water and dried thoroughly several minutes before the experiment. This is to allow the circulation in the finger to become normal. If the hands are clean this washing is unnecessary. A minute or two before the puncture is made the finger is dipped for, say half a minute, in a solution of carbolic acid, about 1 per cent., rinsed with clean tepid water and dried on a clean soft towel or handkerchief. This is also unnecessary, but it prevents soreness following the puncture, and when the fingers are pricked several times a day, for days or weeks continuously, it is a point well worth taking into consideration. Washing with absolute alcohol, followed by ether, is an unnecessary trouble. The finger must be thoroughly dry, however, otherwise the drop will spread. The best place to make the puncture is on the thumb side of the left index finger, a little distal to the root of the nail, and decidedly more towards the palmar than the volar surface. Make the puncture (most conveniently done with the ordinary spring. lance with a spear-shaped blade), and try to regulate the depth so that blood will just not flow witl.out gentle pressure being 46. Richardson: Journal of Med. Research, 1904, vol. xili, pp.
99-102. applied to the finger. The method of procedure now differs according to the depth of the puncture. If the blood emerges the moment the lancet is withdrawn, it should be wiped away promptly with a clean rag, leaving no trace of blood on the skin. If the observer is working alone, on his own finger, a situation like this is inconvenient. He may do one of two things: either make a fresh puncture, not so deep, on another finger and proceed as will be described below for puncture of the proper depth; or he may fill a fresh watch glass about one-third full of the aldehyd fluid, and then, after wiping all blood from the finger, touch the point of puncture to the surface of this aldehyd, and withdraw the finger the instant a fresh drop of blood emerges. The blood and aldehyd are then mixed thoroughly for a few seconds with the glass rod, which must be scrupulously elean, and a large drop of the mixture transferred on the rod to the counting chamber. ${ }^{47}$

This transfer must be accomplished rapidly. A thin clean cover-glass is now laid on, and the chamber allowed to rest quietly for five minutes before counting. This method will give good results, but one can judge better the mixing of the blood and the aldehyd if the puncture is just of sufficient depth for the blood not to flow without gentle pressure. In this case, if working alone, the puncture having been made, proceed as follows:

Twist the handkerchief into a rope. Hold the left hand thumb uppermost, and place the handkerchief in the crotch between the thumb and index finger, with about 15 to $20 \mathrm{~cm}$. lying across its palm, and the rest hanging over its back. Now hold the index finger st:aight and close the other fingers to grasp the handkerchief firmly in the palm. Wrap the handkerchief two or three times around the index finger, beginning at the base and stopping at the last joint; then pass the rest of the handkerchief across the palm and hold it in place with the free fingers. This should be so regulated as not to exert any marked pressure on the index finger, which is kept straight all the while. If any blood has appeared from the puncture, wipe it off thoroughly, with the free end of the handkerchief. Dip the rod in the watch glass full of the aldehyd fluid, and convey about three good-sized drops to the surface of the finger over the puncture. Now bend the last joint of the index finger, and press against the end of the thumb if necessary. This will cause $\therefore$ drop of blood to exude into the aldehyd. Mix the two in situ by passing the end of the rod gently across the top of the blended drop. Do not force the rod into the drop so as to crowd the rod against the blood, or the blood against the finger. Do all this rapidly, and then, on the rod, carry a drop of the blended fluids to the watch glass containing a few drops of aldehyd. Here mix again, without hesitating to dip the rod in liquid, for the plates are fixed by this time, and the watch glass is simply a convenient vessel for farther dilution. Now carry on the rod a large drop of the diluted blood to the counting chamber, and lay on the cover-glass. The same manipulations that apply for getting an even distribution of the blood in erythrocyte counts apply here. The height of the chamber and the flatness of the cover-glass have no bearing on the accuracy, for the object is not to count the absolute number of anything in a known volume, but simply to determine the ratio of the plates to the red corpuscles. After the cover-glass is in position, take a bird's-eye view of the field, first with the low, then with the $\mathrm{hi}_{\mathrm{o}} \mathrm{h}$ power. If the corpuscles are fairly well distributed, allow the chamber to rest quietly for five minutes before counting.

The beginner is apt to take too much blood and not to dilute it enough. The dilution should be such that the red corpuscles do not conceal the plates when both shall have settled to the bottom of the chamber. There should not be more than one or two plates to a small square on the ruled area. The plates settle more slowly than the red corpuscles; hence the five minutes' wait. A longer wait does no harm, for both blood plates and

47. Salvioli employed a rod coated with paraffin, though for a somewhat different method. We find that for our purpose it is not necessary to use paraffin, but the rod must be clean and smooth, and must be wet with aldehyd before it touches the blood. 
red corpuscles are fixed and preserved by the aldehyd. While the chamber is standing for the settling of the blood plates, we may proceed to numerate the red cor. puscles in a different counting chamber, or, if the size of the corpuscles be normal, as in healthy blood, by the hematocrit. The aldehyd fluid we use for the plates makes an excellent counting fluid for the reds, so that no other need be prepared.

It is our custom to count both red corpuscles and plates in six frames of sixteen small squares each. This usually gives about 100 blood plates. In this matter we are guided by our judgment, just as when counting the red corpuscles. If a bird's-eye examination shows the plates and corpuscles to be evenly distributed, and four frames in different parts of the field all give the same ratio, we have, in a few instances, stopped with four frames, while if the distribution was not so regular we have sometimes counted the whole sixteen.

It is a serious mistake to count too few, especially when there is no ruled field under the corpuscles to give an idea of their distribution. The work of some authors is open to this criticism. Petrone, ${ }^{48}$ for instance, in one of his experiments, bases his ratio on as few blood plates as thirty-two. This, we feel, is too small a number to eliminate the error of chance-distribution. When, as in some diseases, the number of blood plates is abnormally low, a larger number of frames should be counted.

Our method of numerating the blood plates without using the Thoma-Zeiss chamber has been given. ${ }^{\mathbf{4}}$ Our experience in this work has been large. We have used it for the past five years in repeated observations on the number of blood plates in blood of twenty-three different healthy individuals; in experiments on the disappearance of the blood plates during coagulation, in which we employed the method of fractional defibrination, ${ }^{50}$ and in an extensive work on the regeneration of blood after hemorrhage-which is yet unpublished.

We were also members of a party of six which went from the University of Illinois to Cripple Creek and Pike's Peak to study the effect of altitude on the blood. In this work we made daily counts of the blood plates for all six of the party for six weeks. A preliminary report of this research is all that has thus far been published..$^{51}$ As a result of this experience we can assert that we have a method which is practical, and which is accurate to such a degree that it will detect many changes in the blood of pathologic cases; changes which should be of value in diagnosis and in prognosis, as well as in etiology.

\section{THE NUMERATION OF THE BLOOD PLATES IN}

\section{PHYSIOLOGY.}

Numeration experiments on the blood of normal individuals have yielded widely different results. We believe this to be due, in the first place, to the different methods employed. This is the explanation which has

48. Petrone: Il Morgagni, 1897, vol. $x \times x i x$, p. 389.

49. See $K$ and $H$ under Methods.

50. Kemp and Callonin: "La numération des plaques dı san aet la relation des plaquettes et des leucocytes avec la coagulation." Arch, ttal, de Biol., 1901, vol. xxxvi, p. 82.

51. Kemp, Stanley, Hayhurst, Harris, Calhoun and Draper. Report of an Expedition, etc., Am. Jour. of Physiology, February, 1904, vol. $x$, p. xxxil. In the presentation of our paper at the Portland session, I gave a considerable account of this altitude work, and still more was brought out in the discussion. It was expected that I should incorporate a full report in the present publication, and it was my intention to do so. I regret, however, that pressure of other work has prevented me from bringing the literature up to date, and from preparing the manuscript. This must, therefore, be reserved for $\propto$ future publication.-Kemp. almost invariably been given, and we do not wish to underestimate its importance, but we are now in the possession of data obtained from our own experiments which lead us to believe that there is another factor which, so far as we know, has been hitherto overlooked, viz., the season and place in which the experiments were made. Our researches have included work done in France, in Switzerland and in different parts of America. In company with Messrs. Stanley, Hayhurst and Draper, we formed a party which went from the University of Illinois to the Rocky Mountains to study the

\begin{tabular}{|c|c|c|c|c|c|}
\hline OBSERVER. & 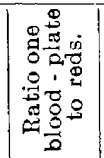 & 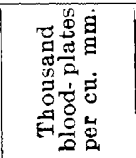 & 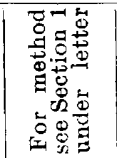 & 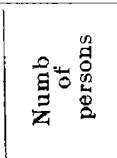 & 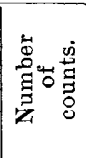 \\
\hline $\begin{array}{l}\text { Afanassiew } 52 \ldots \ldots \ldots \ldots \ldots \\
\text { Bizzozero } 53 \ldots \ldots \ldots \ldots \ldots \\
\text { Brodie and Russell } 20 \ldots \ldots \\
\text { Cadet }{ }^{5 *} \ldots \ldots \ldots \ldots \ldots \ldots \ldots\end{array}$ & $\mid \begin{array}{l}25 \text { to } 18 \\
25 \text { to } 12 \\
9.4 \text { to } 7\end{array}$ & $\begin{array}{c}200 \text { to } 300 \\
210 \text { to } 400 \\
635 \\
100 \text { to } 310\end{array}$ & $\underset{G}{G} \underset{G}{\text { and }} H$ & 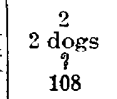 & $\begin{array}{l}24 \\
2 \\
5 \\
9\end{array}$ \\
\hline Determann 5 .............. & $\left|\begin{array}{l}80 \text { to } 18 \\
\text { mean } 22\end{array}\right|$ & $\begin{array}{l}167 \text { to } 278 \\
\text { mean } 227 \dagger\end{array}$ & $G$ and $H$ & 25 & ? \\
\hline Fusarijo $\ldots \ldots \ldots \ldots \ldots$ & ? & $\begin{array}{l}180 \text { to } 250 \\
\text { mean } 200\end{array}$ & $E[?]$ & ? & ? \\
\hline 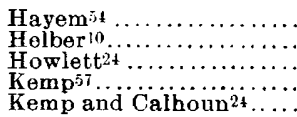 & $\begin{array}{c}20 \\
\cdots \cdots \\
\cdots \\
10.5 \\
5.6\end{array}$ & $\begin{array}{c}200 \text { to } 300 \\
192 \text { to } 264 \\
250 \text { to } 300 \\
457 \\
850\end{array}$ & $\begin{array}{l}\mathbf{E} \\
\mathbf{E} \text { and } \mathrm{J} \\
\mathrm{G} \text { and } \mathrm{H} \\
\mathrm{G} \text { and } \mathrm{H}\end{array}$ & $\begin{array}{c}108 \\
24 \\
\text { few } \\
1 \\
13\end{array}$ & $\begin{array}{c}? \\
? \\
\text { few } \\
5 \\
20\end{array}$ \\
\hline Kemp and Calhoun $58 . .$. & ? & $\begin{array}{l}730 \text { to } 962 \\
\text { me en } 7\end{array}$ & $G$ and $H$ & 19 & 7 \\
\hline Kemp and Calhoun ${ }^{58}$ & & $\begin{array}{l}349 \text { to } 461 \\
\text { mean } 381\end{array}$ & & 10 dogs & 15 \\
\hline $\begin{array}{l}\text { Laker6 } \ldots \ldots \ldots \ldots \ldots \ldots \\
\text { Muirion }\end{array}$ & ? & $\begin{array}{l}400 \text { and } \\
\text { over }\end{array}$ & $G$ and $H$ & $\underset{\text { pigs }}{\text { guinea }}$ & $?$ \\
\hline 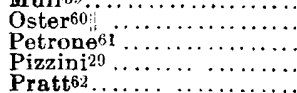 & $\mid \begin{array}{c}q \\
19 \\
15.5 \\
35 \text { to } 10\end{array}$ & $\begin{array}{c}200 \text { to } 2507 \\
250 \text { to } 300 \\
? \\
3005\end{array}$ & $\begin{array}{c}\frac{E}{?} \\
\dddot{G} \text { and } H\end{array}$ & 5 dogs & $\begin{array}{l}? \\
? \\
? \\
? \\
?\end{array}$ \\
\hline 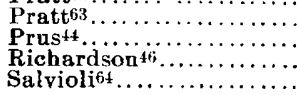 & $\left|\begin{array}{l}24 \text { to } 10 \\
38+7 \\
55 \text { to } 20\end{array}\right|$ & $\begin{array}{c}217 \text { to } 496 \\
500 \\
700 \\
175\end{array}$ & $\begin{array}{l}\ddot{G} \text { and } \dot{K} \\
G \text { and } K \\
G \text { and } K\end{array}$ & $\begin{array}{c}\text { ? } \\
\text { ? } \\
\text { rabbits } \\
\text { rabbits }\end{array}$ & $\begin{array}{l}? \\
? \\
3\end{array}$ \\
\hline Salvioli6t............. & 30 & 213 & $G$ and $K$ & 1 guinea & 1 \\
\hline 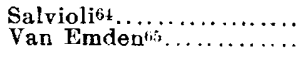 & $\mid 36$ to 40 & $\begin{array}{l}207 \\
245\end{array}$ & $\begin{array}{l}G \text { and } K \\
F^{\prime} \text { and } \mathbf{H}\end{array}$ & 2 dogs & $\frac{2}{?}$ \\
\hline
\end{tabular}

* We regret that we have mislaid most of our notes on Cadet's counts. His paper is for the present inaccessible, so we quote him fndirectly through Hayem, and van Emden. His tables include the work of Hayem and some of his students, as well as Cadet's own. Hayem says that any plate count which does not

+ Determann does not give actual figures; we have calculated them from the ratio for the sake of comparison.

$\$$ Muir gives these figures as a mean, and says that considerable latitude must be allowed on each side. He does not give the extremes. Muir also worked on dogs, but we have not his figures for these experiments in our notes, and Muir's paper is inaccessible to us at present.

If Oster is quoted by Helber, without giving reference to the original work, so we are unable to consult it.

8 These figures are calculated by us from Pizzini's tables. They means.

Pratt gives these ratios, but Indicates that there is a much wider divergence. For this reason we have not calculated the number of plates represented by them. The actial plate counta which Pratt gives in this paper range from 217,000 to 496,000 .

* For Prus' method see under Prus, in section on Methods.

t+ Calculated from Richardson's chart

234

2. Afanassiew : Deutsch. Arch. f. klín. med., vol. xxxv, pp. 233.

53. Bizzozero: Zeltsch, f. wls, Mikroscopie, 1892, vol. ix, p. 232 ; also Arch. ital. de Biol, 1841 , vol. xvi, pp. $389,390$.

54. Cadet: Thèse de Faris, 1881. Quoted from Hayem, "Du Sang," Paris, 1889, pp. 167, 374. Also van Emden: Fortsch. d. Hed., 1898, vol. xvi, p. 250 .

55. Determann: Deutsch. Arch. f. klin. med., 1898, vol. 1xi, p. 371 56. Fusari : Arch. per le sclenze mediche, 1886, vol. x, p. 247. 57. Kemp: Proc. Amer. Physiol, Soc., Amer. Jour. of Physiol. 1902 , vol. vi, p. xi.

58. Kemp and Calhoun: Arch. Ital. de Biol., 1901, vol, xxxvi, p. 83 .

59. Mulr : Jour. of Anat. and Physiol., 1891, vol. xxv, p. 273.

60. Oster: Quoted from Helber, Dentsch. Arch. f. klin. Med. vol. $1 \times x \times 1$, p. 320 .

61. Petrone: Il Morgagni, 1897, vol. xxxix, p. 309.

62. Pratt: Arch. f. exp. Path. u. Pharm., 1903, vol. xlix, p. 304. 63. Pratt: Jour. Med. Research, 1903, vol. x, p. 124

64. Salvioll: Virch. Arch., 1891, vol. cxxv, pp. 378, 393, 394.

65. van Emden : Fortsch. d. med., 1898, vol. xvi, p. 250. 
effect of altitude on the blood. We found that high altitudes have a profound effect on the blood plates; their number is enormously increased, even more than that of the red corpuscles. The full report of that expedition has not been published, ${ }^{51}$ but all notes taken at this time have been worked up, and we may anticipate our report by saying that we believe there are other climatologic conditions beside altitude which affect the blood plates and their relation to the red corpuscles. This will be discussed further on in the present communication, but it is well to bear it in mind in comparing the discrepant results which have been obtained by observers in the past.

For convenience of comparison we have compiled the preceding table. The date of the observation can be told by referring to the literature in the footnote. The actual number of blood plates may be obtained by multiplying the number in column 2 by 1,000 . The method employed is given in the third column. The fluids used may be found in connection with the names of the observers arranged in alphabetical order under Fluids. Each method and each fluid is criticised in accordance with our experience, so we will not comment further on the relative value of the results. A word of caution is necessary in comparing the results in Column 2. Some of the observers have given the maximum and minimum counts which they have ever obtained. Others have given the limits within which they usually find the blood plates to vary. The means in either case are safe to follow; where no mean is given, it indicates that the observer has likely not stated his actual highest and lowest counts.

On comparing the results in Column 2, it becomes apparent that the results of Kemp and of Kemp and Calhoun are more widely divergent than those of any other observer. These facts were, of course, known to us before the figures were tabulated. Without an adequate explanation they would prove that our method could not be relied on. As a matter of fact, however, in examining our records to find an explanation, if possible, we have come on a new and valuable generalization. In our observations ( 12 in the table) it will be noticed that the plate count for dogs is lower than that for man. On general principles this should not be true, and it occurred to us later that possibly the season might have something to do with it. The plate counte which we had recorded on human blood were practically all made during the winter. The work on the dogs was done in May, June and July in connection with some experiments in fractional defibrination. On looking over our records for human blood we find this fact: that the ratios we have determined in winter have al. most invariably been higher than those we found in summer. Moreover, there is less variation from day to day in winter than in summer. This is strikingly shown by some observations which we made in Champaign and Urbana, Ill., before going to Cripple Creek and Pike's Peak to study the effect of altitude. The ratio of plates to reds for the six in the party is given in the following table:

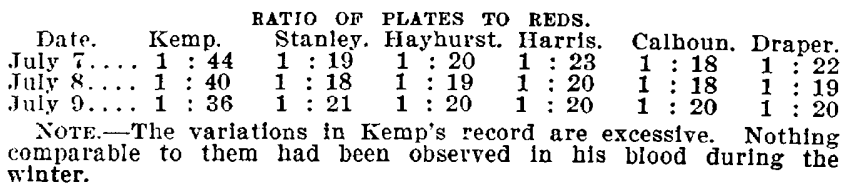

Exactly the same thing holds good at high altitudes, only there we have an increase in the red corpuscles, by the side of a still greater increase in the plates. At high altitudes the variation from day to day in the blood plates of a given individual was remarkably small. In some observations made by one of us (Calhoun) at Escanaba, Mich., during a long-continued spell of dry, very cold weather, it was found that the blood plates behaved much as they did at a high altitude-that is, they not only increased in number, but increased in size. The counts given by Kemp (10 in the table) were made in Paris during the summer. The previous winter counts on his blood were part of the observations of Kemp and Calhoun (12 in table), when the ratio and the plate counts in his blood ran nearly twice as high. A given altitude in the Alps, surrounded by snow, produced a different effect from a corresponding altitude in the Rocky Mountains at the same time of the year. There is great need for careful researches in this field, and they should be long continued and not fragmentary. We propose to continue them ourselves as opportunity affords.

Before passing from this subject we should like to say a word concerning the results which we have quoted from our experiments before going to the mountains. The ratios $1: 44$ and $1: 40$ are the highest we have ever obtained for normal blood. and they stand almost alone. The man (Kemp) on whom the count was made was apparently in perfect health, and there was absolutely nothing subjective to indicate such a condition except the oppressively hot and sultry weather. The count is undoubtedly correct; it was verified by three of the party working on blood from punctures in three different places. In all there were five separate counts made on that blood and they all agreed. It is interesting to note that both red corpuscles and hemoglobin were far from normal also, the red corpuscles were $4,400,000$, the whites 4,500 , the specific gravity 1061.5, and the hemoglobin 56 on the Fleischl scale.

One important fact is set forth by this, viz., that a single abnormal blood plate count should not be taken as indicating a serious pathologic condition. 'The count of the blood plates for that day was 100,000 , and we will see in the section on pathology, which is to follow, that this would have been taken as an indication of a condition more or less serious.

\section{MEALS AND DIGESTION.}

The effect of meals on the count of the blood plates has been studied by a rumber of observers, but their results are not on accord. The experiment most frequently quoted to show that the number of blood plates is influenced by digestion is that of

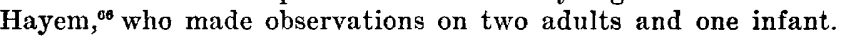
For the adults he found the number of blood plates to be as follows:

First adult-

Morning, fasting . . . . . . . . . . . . . . . . 216,500 One hour after first breakfast (cafe au iait) $\ldots \ldots \ldots \ldots \ldots \ldots 216,500$ One and one-half hours after this breakfast. . . . . . . 350,000 One and one-fourth hours after second brealfast $\ldots \ldots \ldots \ldots 185,000$ after second breakfast........198,000 ours after second breakfast. ........231,000 Second adult-

Morning, fasting. . . . . . . . . . . . . . . . .186,000 One and three-fourth hours after first brealsast (as above) $.218,000$ *This probably consisted of two large cups of bot milk with coffee and one or two French rolls with butter and boney or jam. †This corresponds to our (hot) Iunch, usually taken about 11 clock.

With the exception of the isolated count of 350,000 we believe all the other figures to be within the limits of error, and the second case shows no such rise to prove that the first was due to digestion. Hayem is properly conservative in discussing these results, ${ }^{\circ 7}$ so that he is really misquoted when he is

66. Hayem : Arch. de Physiol., 1878, vol. v, p. 723.

67. Ce n'est qu'un aperçu très-imparfait de l'influence des repas. il sera necessaire de faire un très-grand nombre dobservatrés-égale dans la préparation. 
placed with those who think that digestion influences the number of plates in the blood. We have before us notes from the records of several observers who have investigated this question, but except in prolonged hunger or after a "gorge" no results have been obtained which are not within the limits of error, so we shall not take the space to quote them.

Our own observations have been confined to the effect of the noonday meal. For some of the subjects this was lunch (corresponding to Hayem's "second breakfast") ; for others it was dinner. The afternoon counts tend to be a trifle lower than those of the morning, but they were within the limits of error, so we agree with those who say that meal time, as such, has no effect on the number of plates in the blood. On Pike's Peak (altitude 14,200 feet) we noticed enormous differences between morning and afternoon counts, but we do not believe that mealtime had anything to do with this, for we all ate a hearty breakfast and no counts were made fasting.

\section{v. THE NUMERATION OF BLOOD PLATES IN PATHOLOGY.}

We are strongly of the opinion that the blood plates, in pathology, offer a field for investigation which is unusually attractive in its promise of good results. This field is like a rich country which has been undeveloped owing to the lack of railroads. The methods which have been employed heretofore in numerating the blood plates have been either inaccurate or laborious or both. We believe that our method removes each of these objections to a large extent, and we trust it will be of service in opening up the new territory.

The literature on the numeration of blood plates in pathology is becoming voluminous. It contains records of some work which is of great value, and of some which is almost if not quite worthless, owing to faulty methods. On the other hand, some of the observers who have employed faulty methods have accompanied their records with clinical histories which are very complete, and their findings for the blood plates are, on the whole, interesting and suggestive in spite of errors of experimentation. We first attempted to classify this work under the heads of the different diseases, but gave it up, as it would require such a discussion of individual cases as to be far beyond the scope of a general paper on the subject. We next attempted to classify the work under the heads of diseases in which the plates are increased and those in which they are decreased in number. We abandoned this, also, because it would do more harm than good simply to quote $\mathrm{A}, \mathrm{B}$ and $\mathrm{C}$ as finding that the plates were increased in erysipelas, for instance, while $D, E$ and $F$ found them to be decreased. This has been done in existing literature, and on consulting the original papers we find that $A$ employed a method which could not be trusted; that B makes his statement from observations on only one case, while $\mathrm{C}$ gives clinical histories showing complications which would certainly have to be allowed for. We have gone over all the literature which we have seen recorded, and, therefore, hope that we are reporting the subject up to date. After deliberate consideration we are convinced that the best way to present this information is by authors, arranged in alphabetical order. The reference in the footnote will give the year. We will state the method and the fluid employed, so that one may judge of the accuracy of the experiment by referring to the first section of this article for the method, and to the second section for the fluid. We will also state the number of cases reported by a given author, and the footnote will show by page where these records may be found. The list of diseases investigated by each author will be given in the same order as it appears in his paper. This will save undue multiplication of foot- notes. The study and criticism of the case records, etc., in any given disease, must be left to those who are making that disease a special subject of investigation. There are a few general points which seem to be concurred in by practically all observers. These will be given at the close of the article in the summary.

AFANASSIEW.-Afanassiew ${ }^{\mathrm{s}}$ used the pipette method with Afanassiew's fluid. He reported cases as follows:

Leucemla $\ldots \ldots \ldots \ldots \ldots$ case Erysipelas, faclal $\ldots \ldots \ldots 1$ case Typhoid fever........ Gastric ulcer......... cases Icterus gravis.......1 case

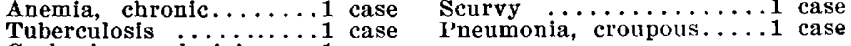
Cachexia, mala rial........ case

AoYoma.-Aoyoma ${ }^{6 \theta}$ makes no count and gives no special method. His method is presumably A, Section 1. He states that the blood plates are increased in bubonic plague.

CADET.-Cadet ${ }^{31}$ used the pipette method (E), with fluids described under "Cadet." He reported pathologic cases, especially continued fevers. ${ }^{20}$

Denys.-Denys ${ }^{21}$ did not make actual counts. The method used is not stated. He reported four cases of purpura hemorrhagica.

DetermanN.--Determann ${ }^{72}$ used the ratio method ( $G$ and H), with Bizzozero's fluid. He reports 85 pathologic cases, and gives clinical and postmortem notes. His cases are:

Fibroma $\ldots \ldots \ldots \ldots \ldots$ case Chlorosis $\ldots \ldots \ldots \ldots .6$ cases Struma parenchymatosa.1 case Anemia . ............ case Phthisis pulmonalis....8 cases Hemorrhage (chronic) ...2 cases Bronchitis (acute) .....4 cases Sarcoma ............ case Emphysema . ........1 case Serositis tuberculosa....2 case Heart disease, (different

forms) $\ldots \ldots \ldots \ldots \ldots .2$ cases Syphilis $\ldots \ldots \ldots \ldots \ldots 1$ case Lead poisoning (chronic) Gastric catarrh Gastric catarrh (chron- 1 case Nephritis (chronic), interstittal ........... 2 case Polyarthritis deformans. 1 case Eclerosis, (multiple) .....1 case Cerebral tumor $\ldots \ldots \ldots 1$ case
Spinal disease (chronici.2 Spinal disease (chronic) .2 cases
Hysteria Hysteria $\ldots \ldots \ldots \ldots \ldots \ldots 1$ case

Peritonitis (perforation)
'Tuberculosis (bones and juberculosis (bones and Anus preternaturalis ...3 cases Empyema (rib-resection) 1 case Pregnancy $\ldots \ldots \ldots \ldots \ldots .8$ cases
Childbirth $\ldots \ldots \ldots \ldots .2$ cases Infancy (newborn) ........ Infancy (newborn) .......... case cterus neonatorum...... case yemia $\ldots \ldots \ldots \ldots \ldots$ case Iyphoid fever........4 cases arysipelas $\cdots \ldots \ldots \ldots j$ case Rheumatism, (acute art.) 2 cases

FUSARI.-Fusari ${ }^{\text {To }}$ used the pipette method (E), with fluids recorded under Fusari. He reports the following cases:

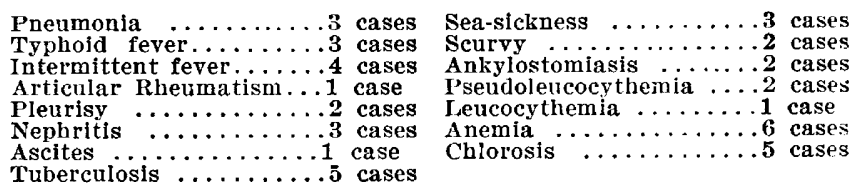
Tuberculosis ..........

Grawirz.-Grawitz ${ }^{74}$ reports that he has found the plates to be increased in chlorosis. He uses the expression "soweit man nach Schätzungen urtheilen darf, and when criticising the results of previous observers who had made actual numerations, he mentions no method of his own, so we surmise that he used method $A$ as already described.

Halla.-Halla ${ }^{35}$ uses the method of direct examination (A); but he is so conservative that we quote him to show that some results even when obtained by a faulty method may be of value. He says: "Familiar as I was with the blood plates, I could not help noticing them in my examination of the blood (for other purposes) in pathologic cases." He goes on to say that he does not attempt any exact count, but by rapid examination of the blood, as soon as possible after it is drawn, before the plates have greatly altered in shape, he could de-

68. Afanassiew : Deutsch. Arch. f. klin. Med., 1894, vol. xxxv, pp. $236-239$.

69. Aoyoma: Mitthellungen aus d. med. Fac. d. Kaiserlich-Japanischer Univ., Tokio, 1895, vol. iti, pp. 219, 220.

70 . We regret that our notes on his pathologic cases are mislaid and that his article is now inaccessible to us.

71. Denys : Centrlbl. t. allg. Path, und path. Anat., 1893, vol. iv, pp. $175,177$.

72. Determann: Deutsch. Arch. e. klin. med., 1898, vol. lxi, p. 371 et seq.

73. Fusari : Arch. per le scienze mediche, 1886, vol. x, p. 249.

74. Grawitz: "Klinische Pathologie des Blutes," 1896, pp. 4כ and 80 .

75. Halla: 7eitsch. f. Heilkunde, 1883, vol, iv, pp. 231, 232, 331 et seq. 
termine "without difficulty," whether the number of plates was above or below the normal. We would be inclined to doubt this, especially the "without difficulty," and to feel that Halla's observations were too finely drawn, but when he states, further, that "only the grossest, most striking quantitative changes" were taken into account, we feel that such generalizations, based on a sufficiently large number of observations, are not to be discarded as entirely without value. The pathologic cases which he reports are the following:

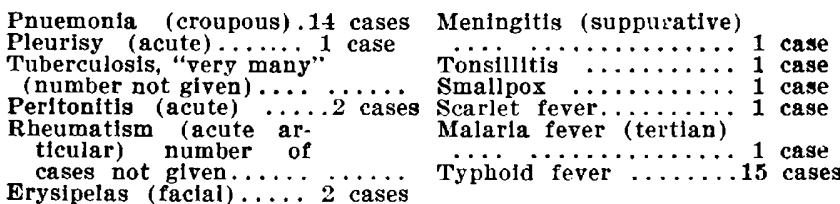
Erysipelas (faciai) $\ldots \ldots 2$ cases

HAYEM.- - Hayem used the pipette method (E), and several different fluids which are described under his name. His publications on pathologic cases are scattered through a wide literature, but he has gathered his results in his classic large monograph,$^{78}$ and his findings in the different diseases may be consulted in the proper chapters. He has also published a later work $\mathrm{k}^{35}$ in which he brings his treatment of the subject up to date. Hayem may be said to have re-discovered the blood plates, ${ }^{77}$ and his earlier work was the starting point for the modern study of those elements. His hematoblast theory has not met with acceptance, but, apart from this, his pioneer researches on anemias, ${ }^{78}$ on purpura hemorrhagica ${ }^{78}$ and on a blood crisis $^{\text {so }}$ in certain fevers ${ }^{\text {si }}$ have yielded results which have been confirmed by nearly every later observer, whatever has been the method employed. (See summary, at the end of this article).

Hencer.-Helber ${ }^{32}$ used the pipette method with a special counting chamber. These are described in methods $\mathbf{E}$ and $\mathrm{J}$. The fluid he used is described under his name. He reports the following cases:

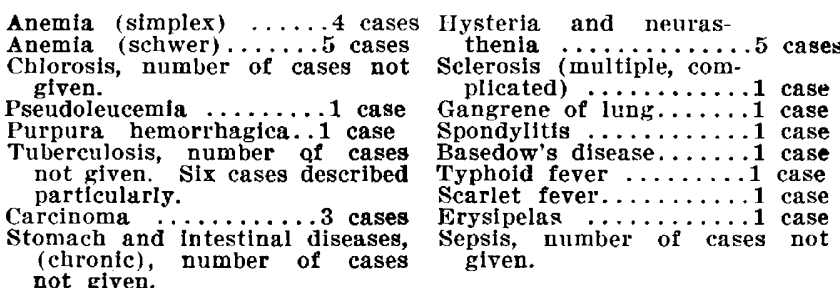
not given.

HowleTT.-Howlett ${ }^{83}$ used the pipette method (E), with Gowers' hemocytometer for counting the plates in normal blood. He reports one case of pernicious anemia, in which he says the number of plates was sometimes normal and sometimes away below. He does not say he counted the blood in this case and from the context we judge that he used method $A, B$, or D. If D, he probably diluted with Hayem's solution A.

Laptschinsky.-Laptschinsky $y^{84}$ did not count the plates. His experiments were mostly on ordinary wet preparations and he refers to the "granular masses of Max Schultze" rather than to the isolated plates. This work was before Hayem's paper which brought the plates into prominence.

MuIR.-Muirss used the pipette method (E). His fluid is described under his name. He has examined pathologic blood

76. Hayem : Du Sang, Paris, 1889

77. Hayem: Comp. rend. de l'Acad. des Sciences, 1877, vol. lxxxiv, pp. 1239-1242: Arch. de Physiol., 1878, pp. 692-734; Id. 1879 , pp. $201-261$, and $577-613$.

78. Hayem: Gazette méd. de Paris, 1880 , pp. 119-120; 191-192; 215-216 ; Compt. rend. de l'Acad. des Sciences, 1880, vol. xc, pp. 225-228 ; Id., 1883, vol. xcil, pp. 82-92.

79. Hayem's first plate counts in purpura were in 1890 . See "Lecons sur les Maladies du Sang," pp. 527-528.

80. In hls earlier works Hayem calls this a crise hématique; In his later ones he calls it a criso hématoblastique.

81. Hayem: Compt. rend. de l'Acad. de Physiol., 1882, vol. xciv, pp. 200-202. Also, Arch. de Physiol., 1883, vol. Il, pp. 247-256.

82. Helber: Deutsche Arch. f. klin. Med., 1904, vol. Ixxxi, p. 320 et seq.

83. Howlett: Lancet, 1882, vol. 1, pp. 223-224

84. Laptschinsky: Centralbl. f. d. med. Wiss., 1874, p. 660.

85. Muir: Jour. of Anat. and Physiol., 1891, vol. xxv, pp. 259 et seq., and 364 et seq. in "upwards of one hundred cases." The results of many of these examinations he has not published, but the more important ones he has tabulated and often has added very full notes. His tabulated and annotated cases are as follows:

Hemorrhage $\ldots \ldots \ldots \ldots$ cases Lencocythemia $\ldots \ldots \ldots 3$ cases Anemia (pernicions) $\ldots 12$ cases Lymphadenoma $\ldots \ldots \ldots 7$ cases Chlorosis ...........14 cases Cases with high tem-

Anemia (secondary)...11 cases perature .........5 cases

nemia (miscellaneous) 5 cases

Pizzrni.-Pizzinis ${ }^{\text {se }}$ used the ratio method ( $G$ and $H$ ), with an osmic acid fluid as described under his name. The pathologic cases examined by Pizzini were as follows:

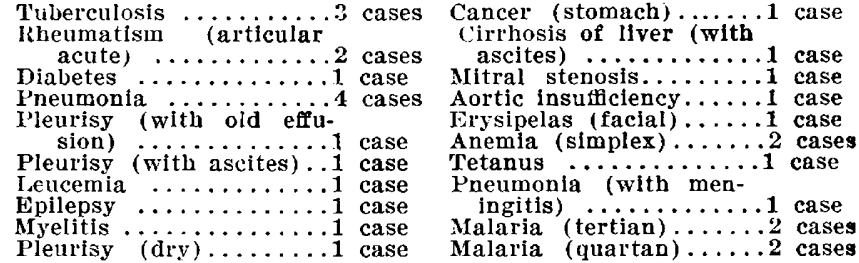

Pratr.-Pratt ${ }^{8 z}$ used the ratio method ( $G$ and $K$ ), with a fluid described under his name. The pathologic cases which he reports are:

P'urpura hemorrhagica...1 case Chlorosis, number of cases not reucemia ............. cases Anemia (perntclous) ....10 case Anemia (secondary), number of cases not mentioned.

eacemia myelogenous, number mentioned.

Erythrocytosis, number of case not mentioned.

severe hentorrhage, number of

of cases not mentioned.

Prus.-Prus ${ }^{44}$ counted the plates by the pipette method (E and $G$ ), but he used a special fluid, described under his name, which made his method unique. He reports four cases on leucocythemia.

Preisicil And Heim.--Preisich and Heim ${ }^{\text {ss }}$ report one case of pernicious anemia, in connection with their studies on the origin of the blood plates.

RIEss.-Riess ${ }^{89}$ does not count the plates, he simply states whether they are increased or decreased. We infer that he used method A. Riess' work is among the earliest; it was done before any definite method of counting the plates had been suggested. He reports on the following diseases, the number of cases is not given:

Anemia (pernicious).

Anemia (simplex).

Cachexias (such as cancer).

Profuse nemorrbage (repeated) reucemia.

Pseudoleucemia.

SALvioli.-Salvioli ${ }^{16}$ uses the ratio method ( $G$ and $\left.K\right)$. His work was on the blood after severe burns.

SchleIP.-Schleip ${ }^{\circ 0}$ used method D. He reports fifty-seven cases of trichinosis during the Homburg epidemic of 1903 .

TÜrR.-Türk ${ }^{\circ 1}$ used method A. The plates were never counted. The blood was taken undiluted and in thin layers (at a room temperature) and examined as quickly as possible. Türk himself points out that this method is very defective owing to the adhesive properties of the blood plates. He does not attempt to give numbers, but simply speaks of the plates as "reichlich vermehrt," "kaum vermehrt," etc. $\mathrm{He}$ also checked his observations by the examination of dry preparations. See method D.

VAN EMDEN-_-Van Emden ${ }^{92}$ used method F, with Prus fluid. We feel that his results are trustworthy. His records are accompanied by interesting clinical notes. The eases which he reports are as follows:

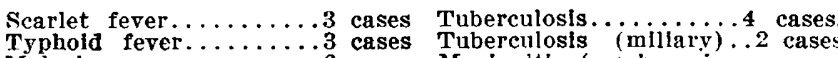
Malaria $\ldots \ldots \ldots \ldots \ldots$ cases Meningitis (cerebrospin. Erysipelas $\ldots \ldots \ldots \ldots 2$ cases al) $\ldots \ldots \ldots \ldots \ldots \ldots 2$ cases

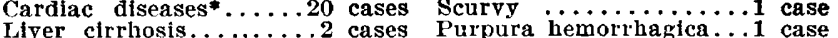
Liver cirrhosis............ case

*These cases involve so many interesting complications that we can not classify them here. The reader is referred to the original.

86. Pizzinl : Riforma medica, 1894, vol. 11, pp. 376 and 387 et seq 87. Pratt: Johns Hopkins Hospital Bulletin, 1905, vol. xvi, p. 201 88. Preisich and Heim : Virch. Arch., 1904, vol, clxxvili, p. 59. 89. Riess : Berlin. klln. Wochft., 1879, p. 696.

90. Schlelp: Deutsches Arch. f. klin. Med., 1904, vol. lxxx, pp. 11-17.

91. Türk: Klinlsche Untersuchungen, etc., Vienna, 1898, pp. 15 , $16,22,121,173,181,217,219,250,276,294,315,344$

92. van Emden: Fortsch. d. med., 1898, vol, xvl, p. 282 et seq. 
For many ther cases not mentioned in his German paper, Van Emden refers to his inaugural dissertation in Dutch, Leyden, 1896.

SUMMARY.

From a great mass of conflicting evidence, most of it obtained by methods of questionable accuracy, we may cull three important generalizations which are almost unanimously agreed on-whether the method of the observer was good, bad or indifferent. We, therefore, feel it safe to predict that they will become established facts. It is interesting, furthermore, to note that these were all pointed out by Hayem, who was the first to make approximately accurate numeration experiments on the blood plates.

The first of these generalizations relates especially to acute infectious fevers; the second, to different forms of anemia; the third, to purpura hemorrhagica. We will consider each in order.

Acute Infectious Fevers.-During the course of an acute infectious fever (especially typhoid) the number of blood plates is usually either subnormal or normal. If the fever breaks by crisis, the crisis is accompanied by a rapid and striking rise in the number of blood plates. This is the classical "crise hématique" or "crise hématoblastique" of Hayem. If this "crise hématique" fails to appear, it is the sign of some masked complication which is usually unfavorable. Most observers have found that this is true of all acute infectious diseases, but all are practically agreed on typhoid. ${ }^{93}$ The study of the plates in pneumonia has been especially interesting. As a rule, observers have found a marked blood crisis, but they are not in accord as to whether the plates are increased or diminished during the continuance of the fever. On some other fevers there has been a wider divergence of opinion. The study of the leucocytes in fevers has attracted considerable attention. We believe that further investigations on the blood plates in fevers would lead to valuable results, besides being of use in diagnosis and prognosis for the cases under observation.

Anemias.-In the different anemias, there is a remarkable concurrence of opinion that the plates may or may not be diminished in secondary anemias-indeed, in most cases, they are reported to be increased; while in pernicious anemia they are always greatly diminished. An increase above the normal in the number of the blood plates excludes the diagnosis of pernicious anemia. If a case under treatment shows an increase in the number of the blood plates, the prognosis is encouraging; if, in spite of all that can be done, the plates continue to fall in number, the prognosis is almost certainly fatal. In this connection we can not do better than quote from the latest work of the veteran observer Hayem, ${ }^{94}$ who speaks with especial emphasis on the study of blood plates in anemias. He says: "It is certainly wrong to neglect these elements. When their number becomes small it is always a more or less serious sign; when they become rare the retractability of the clot diminishes.

This double lesion rarity of the hematoblasts [blood plates] and loss of retractability of the clot) is a sign of progressive pernicious anemia, and is the most characteristic sign which we

93. Van Emden agrees with the rest in finding a "crise hematoblasticue" in typhoid, but be says it is much less marked than in pneumonia, scarlet fever, measles, and erysipelas. In malarial feve (Sumpfieber) the "crise bematoblastique" resembles that of ty. phoid.

94. Hayem: Iseçons sur les maladies du Sang, Paris, 1000, p 328 et seq. have of this protopathic form." If this double sign does not exist, the proper treatment will effect a cure and one of the first signs of improvement is a rise in the number of blood plates. If the case continues to improve, further interesting changes are noted in the relation of the plates to the red corpuscles; small red corpuscles appear in increasing numbers and there is every indication that young red corpuscles are developed from the plates. ${ }^{95}$ Hayem's observations, so far as the numerical relations of the blood plates are concerned, have been confirmed by a number of observers, including van Emden and Pratt, whose methods of numeration are free from the objections which apply to the older method of Hayem.

Purpura Hemorrhagica.-In purpura hemorrhagica the number of blood plates is enormously diminished. Van Emden and Pratt each state that the lowest counts they have ever found have been in this disease. Hayem called attention to the slowness in clotting of the blood. Helber confirms this observation of Hayem. To distinguish the blood in purpura hemorrhagica from that of pernicious anemia, Hayem ${ }^{96}$ says that, in the absence of appreciable changes in form in the red corpuscles, "the scarcity of hematoblasts [blood plates] and the absence of serum after the coagulation of the blood, are two signs which are constant and pathognomonic" of the disease. The few plates which are found are often of large size. The blood contains masses of small plates, but these are broken down. Fibrin threads in the clot are few, but coarse. Recovery is ushered in by a "crise hématoblastique."

\section{APPENDICITIS; IDEAS CONCERNING MANAGEMENT, BASED ON ONE THOUSAND OPERATIONS.* \\ VAN BUREN KNOTT, M.D. SIOUX CITY, IOWA.}

It is not my purpose to enter into an exhaustive dissertation on the subject of appendicitis. The field has been most thoroughly covered during the past few years, and so far as its etiology, pathology, symptomatology and diagnosis are concerned, the opinion of the profession may for practical purposes be said to be in accord.

This can not as yet be said, however, concerning the treatment of the disease, as honest differences of opinion still exist, many of them varying only in degree, but sufficiently marked to convey to numerous members of the profession the idea that the treatment of appendicitis is a subject still more or less sub judice.

Actuated by the belief that the various phases of the question-how shall we manage our appendicitis patients?-may be best answered by a study of the methods employed by various men, I venture to add my testimony to the large mass of evidence already in print.

During the years 1893 to 1905 inclusive I have operated on 1,024 cases of appendicitis. Of this number 640 were clean cases and 384 were pus cases. By clean cases I mean those in which the infection was still confined within the appendix; by pus cases those in which the infection had escaped from the appendix and established a septic process, localized or diffuse. Of the total

95. Hayem's discussion of this whole question is most interesting; the text is fllustrated by a curve showing the changes in the different corpuseles and in the hemoglobin. It will well repay one to consult the origlnal.

96. Hayem: I.econs sur les maladies du Sang, Paris, 1900, pp 530 et seq., and 540 .

* liead at the annual meeting of the Western Surgical and Gynecological Association, Kansas City, Mo. 